\title{
Fire resistance of concrete-filled steel tube columns with preload. Part II: Numerical and Analytical Investigation
}

\author{
Min Yu ${ }^{\mathrm{a}, \mathrm{c}}$, Tan Wang ${ }^{\mathrm{a}}$, Weijun Huang ${ }^{\mathrm{a}}$, Jianqiao Ye $\mathrm{e}^{\mathrm{b}, *}$ \\ a. School of Civil Engineering, Wuhan University, Wuhan 430072, China; \\ b. Department of Engineering, Lancaster University, Lancaster, LA1 4YR, UK \\ c. Engineering Research Center of Urban Disasters Prevention and Fire Rescue Technology of Hubei Province, \\ Wuhan 430072, China;
}

\begin{abstract}
Cast-in-situ concrete-filled steel tube (CFST) structures are inevitably subjected to preload that are developed in the steel tube during the construction process. These preloads may have detrimental effects on the overall performance of a CFST component, such as a CFST column, especially when the column is subjected to elevated temperature. However, existing design methods of CFST exclude the impacts of preload in fire resistance design. In this paper, a three-dimensional finite element model for predicting fire resistance of CFST with preload is developed and validated by experimental tests. The model is then used to predict fire resistance time of CFST columns with different slenderness, load and preload ratios. The results show that preload of the steel tube have little influence on the fire resistance of short CFST columns, while the influence of preload on the fire resistance can be significant when the slenderness ratio is greater. Further increase of the slenderness ratio exceeding a certain range, however, reduces the effect of preload. It can be generally concluded that fire resistance of slender CFST columns decreases with increase of preload ratios and the effect of preload on fire resistance of CFST columns is more prominent when the load ratio is greater. In addition, formulas for calculating fire resistance of cast-in-situ concrete-filled steel tubes (CFST) with preload are proposed. This paper is a companion paper of [24].
\end{abstract}

Keywords: Concrete-filled steel tube (CFST); Preload; Fire resistance; Finite element method; Unified formula

\section{Notations}

$A_{s}, A_{c}$

$\bar{T}_{s}, \bar{T}_{c}$

$f_{y}$

$f_{y, \bar{T}_{s}}$

$\underline{f_{c k}}$

$\bar{f}_{c k, \bar{T}_{c}}$

$N_{t}$

$N_{\text {pre }}$

$N_{0}, N_{0, s}$

$N_{E k}, N_{s, E k}$

$N_{c r}, N_{s, c r}$

$N_{0, T}, N_{u, T}, N_{c r, T}$ area of steel and concrete, respectively

average temperature of steel tube and concrete core, respectively

characteristic strength of steel tube

equivalent strength of steel tube at $\bar{T}_{s}$

compressive strength of concrete

equivalent strength of concrete at $\bar{T}_{c}$

total axial load applied to column

preload applied to steel tube

characteristic plastic resistance of CFST column and steel tube, respectively

characteristic buckling load of CFST column and steel tube, respectively

Euler buckling load of CFST column and steel tube, respectively

characteristic plastic resistance, ultimate capacity and Euler buckling load at elevated temperature of CFST column, respectively 


\begin{tabular}{ll}
\hline$\frac{\lambda}{\lambda_{s c}, \bar{\lambda}_{s c, T}}$ & slenderness ratio of column \\
$r$ & normalized slenderness ratio at room and elevated temperature, respectively \\
$\alpha$ & load ratio \\
$\beta$ & imperfection factor \\
$\eta_{\text {pre }}$ & preload ratio, $\beta=N_{\text {pre }} / \varphi_{s} N_{0, s}$ \\
$\xi_{p r e}$ & preload reduction factor, $\eta_{p r e}=\varphi_{s c, p r e} / \varphi_{s c}$ \\
$\varphi_{s c, p r e}$ & preload influence factor \\
$\varphi_{s}, \varphi_{s c}$ & stability factor of a CFST column considering preload \\
$\varphi_{s c, p r e, T}, \varphi_{s c, p r e}$ & stability factor of a steel column and CFST without considering preload, respectively \\
$\theta$ & temperature dependent stability factor of a CFST column with and without \\
& considering preload, respectively. \\
& confining coefficient, $\theta=f_{y} A_{s} / f_{c k} A_{c}$
\end{tabular}

\section{Introduction}

Concrete-filled steel tube (CFST) columns have been widely used in many practical construction designs, as they offer excellent static and seismic performance. CFST columns are also efficient and economical in construction by making full use of the strength and stiffness of the hollow steel tube and the early-age concrete. However, it was recognized that during the course of construction, preload, which also includes the initial stresses in the steel tube induced by shrinkage and creep of concrete ${ }^{[1]}$, had to be considered in the design process ${ }^{[2]}$. At present, the research on the effect of preload on the performance of CFST is mainly focused on studying their axial strength under room temperature. Clearly, with increasing demands for life cycle analyses and fire prevention in modern designs, it is very important to study fire resistance of CFST columns considering the effect of preload induced from construction process and aging of structures.

To the authors' best knowledge, the work reported in the literature in this aspect are either on fire resistance of CFST without considering preload or on the bearing capacity of preloaded CFST at room temperature. For example, a numerical model for calculating fire resistance time of circular CFST was developed by $\mathrm{Lie}^{[3]}$. Fire resistance of CFST was calculated using finite element method by $\mathrm{He}^{[4]}$. Based also on finite element analysis, Yang ${ }^{[5]}$, Dai ${ }^{[6]}$, Chung ${ }^{[7]}$, Hong ${ }^{[8]}$, Espinos ${ }^{[9]}$, Yu, at al ${ }^{[10]}$ have all carried out numerical investigations on fire resistance of CFST, where a range of design parameters, except preload, were evaluated. Under room temperature, the effect of preload on the bearing capacity of short and slender CFST columns as well as axial and eccentric compression members were studied by Xiong ${ }^{[11]}$.

Experimental study is generally the preferred method to study a CFST with preload ${ }^{[12,13]}$ and its fireresistance ${ }^{[14-17]}$. A more detailed review on relevant experimental studies can be found in the companion paper [24]. It is also essential in the study of fire resistance of CFST to develop a reliable numerical model to replace expensive tests and simulate complex loading and support conditions. As a companion paper of ${ }^{[24]}$, this paper attempts to study the influence of preload on fire resistance of CFST both numerically and analytically. A finite element model on fire resistance of preloaded CFST, which is valid for both room and elevated temperature, is developed and validated against available test results. The effect of preload on fire resistance of CFST is studied numerically for both short and slender columns subject to a range of load and preload ratios. The temperaturedependent stability factor of CFST columns considering preload is developed also to calculate the characteristic axial resistance of preloaded CFST at elevated temperature.

*Correspondence author: J.Ye (j.ye2@lancaster.ac.uk) 


\section{Finite element modeling of preloaded CFST under fire}

\subsection{Finite element modeling}

\subsubsection{Material modeling at room and elevated temperature}

The thermal properties used in this paper, including density, specific heat, conductivity and coefficient of thermal expansion of both steel and concrete, are taken from Lie ${ }^{[18]}$. For the mechanical analysis, the elastic modulus, ultimate strength and ultimate strain are all temperature dependent. For steel, von Mises yield criterion is adopted and the uniaxial stress-strain relation is assumed bilinear. The temperature dependent yield strength $f_{\mathrm{y}, \mathrm{T}}$ and elastic modulus $E_{\mathrm{T}}$ can be found in $\mathrm{Lie}^{[18]}$, and the secant modulus of concrete is $0.01 \mathrm{E}$. For concrete, the elastoplastic damage constitutive model is adopted for both room and elevated temperature, and the uniaxial compressive stress-strain relation is from Eurocode 4 (EN 1994-1-2:2005) ${ }^{[19]}$, where two curves are provided for both room and elevated temperature. Figure 1. Normalized stress-strain curves of concrete

(a) shows the comparisons between the two Eurocode 4 curves and the one from GB50010-2010 ${ }^{[20]}$ for concrete at $20^{\circ} \mathrm{C}$. It is clear that the nonlinear descending branch of GB50010-2010 agrees well with the EC-4Curvilinear model. Thus, the curvilinear model will be used in this paper so that the results of the paper will have wider applications. Figure 1(b) shows the stress-strain curves of the EC-4-Curvilinear model at different temperatures. More discussions on the constitutive laws of steel and concrete at elevated temperature can be found in the literature ${ }^{[10]}$.

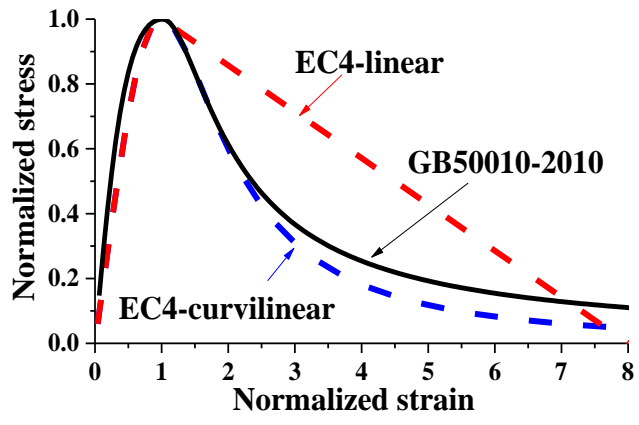

a) Normalized stress-strain curves at $20^{\circ} \mathrm{C}$

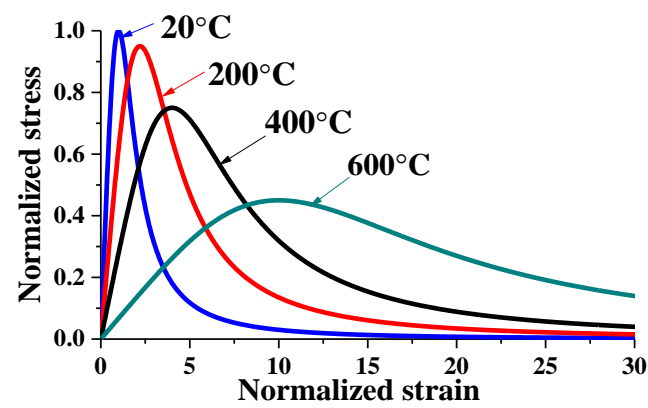

b) Normalized stress-strain curves

Figure 1. Normalized stress-strain curves of concrete

\subsubsection{The finite element model of preloaded CFST under fire}

In the authors' previous work ${ }^{[10]}$, a FE model was developed for fire resistance analysis of CFST without preload. FE models were also developed for CFST subjected to preload at room temperature, e.g. by Xiong [11, 12]. To consider the combined effect of preload and temperature on fire resistance of a CFST column, a preload is applied to the steel tube first to simulate any preload introduced before and during the course of casting concrete. The steel and the solid concrete core will then act together in the fire resistance analysis. To develop a model that can take into account of the above two stages, the following new features are introduced.

(1) To accurately calculate fire resistance of CFST, interface slip and separation caused by different thermal expansion of the steel and concrete must be considered. The interface is defined as a 'contact' ${ }^{[11]}$, where the 
contact component in the normal direction is defined as a "Hard" contact, and in the tangential direction the contact is frictional. The coefficient of friction can be determined by experiments.

(2) To simulate preload under room temperature, the element 'birth and death' technique is used to deactivate and activate concrete elements, so that the concrete elements are 'removed' from the model when the preload is developing in the steel tube and 'added' to the model after the preloading stage is completed. Obviously, this procedure results in a model that was preloaded only in the steel tube (developed before casting concrete). Due to the action of the preload, deformation occurs in the steel tube. Therefore, in order to make sure that the activated concrete elements are connected to the same nodes of the steel elements before deactivation, all the concrete elements are activated by a 'strain free' approach that considers the contact between the concrete and the steel as a 'tie'.

From the above steps, it can be seen that to account for the slip and separation between the tube and the concrete, the interface between them has to be considered as a as a 'tie' for preload analysis while as a 'contact' for fire resistance analysis. The preload and the following fire resistance analyses have to be conducted sequentially, with the above two different interfacial contacts being implemented at different stages of the analysis. To this end, the "duplicate element" method is used, by which the duplicated elements are used to discretize the space that will be occupied by the solid concrete core after the preload stage.

Figure 2 illustrates the components, contacts and boundary conditions for the FE analysis to be carried out. It is noted that in Figure 2:

(1) The duplicate elements are 'virtual elements' at the positions matching each of the 'real' concrete elements for simulating the CFST when the preload is applied. The duplicate elements are elastic with a very small elastic modulus (e.g. 1Pa), which is to ensure that the steel tube carries virtually all the preload at the preload stage.

(2) The interface between the steel and the real concrete is defined as 'contact', while the interface between the steel and the duplicate elements is defined as 'tie'. The introduction of the duplicate elements is to meet the need for switching the interface property from' tie' to 'contact' before fire resistance analysis starts. The selection of 'Master' and 'Slave' surfaces shown in Figure 2 is to avoid the situation where a surface is defined as a 'Slave' surface of multiple 'Master' surfaces, which is not permitted by the software.

(3) The two ends of the column are defined as 'analytical rigid' that, theoretically, have infinitive stiffness, on which boundary conditions are conveniently imposed. Separate analytical zones are defined, respectively, for the steel and concrete parts of the end, so that the axial forces on the steel tube and the concrete core can be individually calculated. 


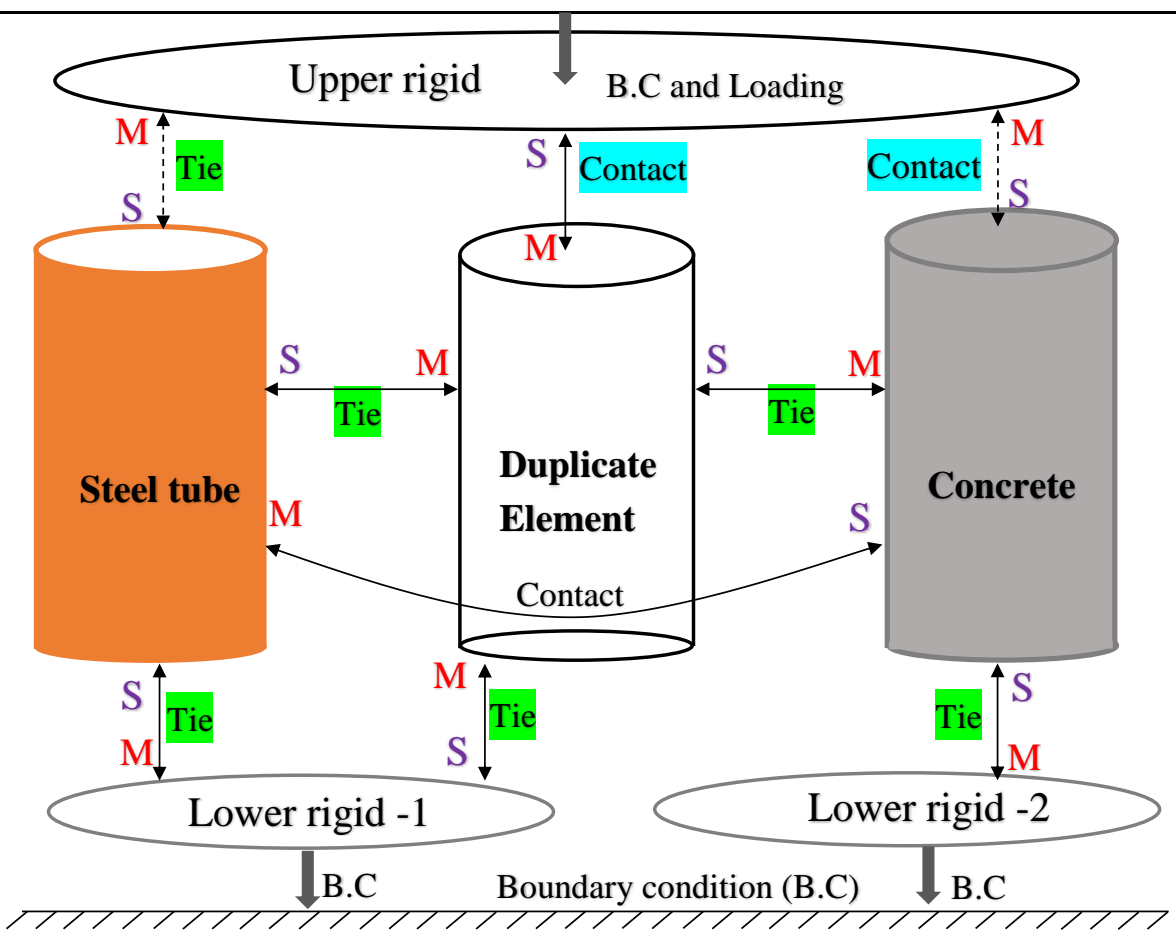

Note: 'M' and 'S' denote 'Master surface' and 'Slave surface' of a contact pair, respectively;

'Rigid' denotes 'analytical rigid' that is not deformable.

Figure 2 Contacts and boundary conditions of FE model
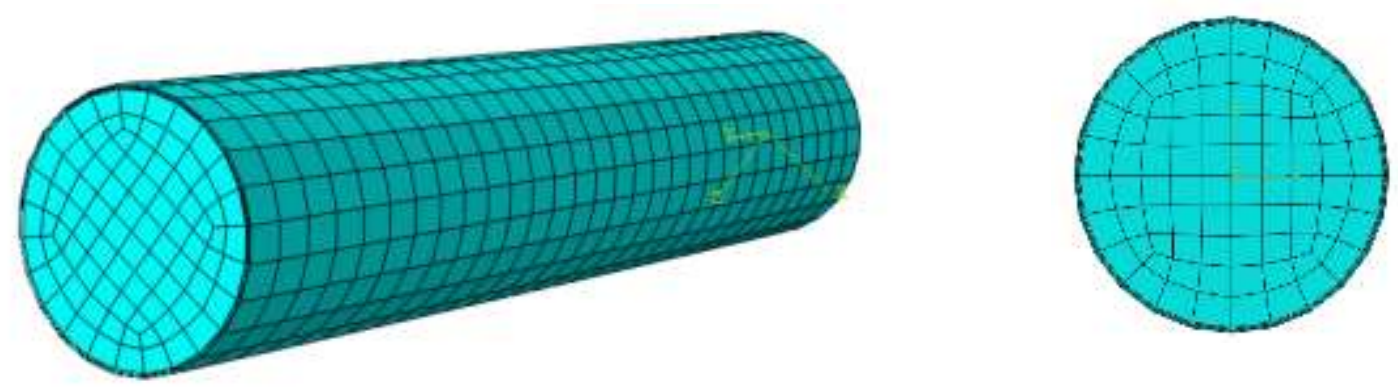

Figure 3. Finite element model of CFST column

To include stability analysis in the model, a $l_{0} / 1000$ initial bending deformation ${ }^{[20]}$ was taken into account, where $l_{0}$ is the initial height of the tube. Other details of the FE model, such as meshing generation, etc. are the same as in $\mathrm{Yu}$, et al ${ }^{[10]}$. In the finite element analysis, 3D solid elements were used for both the steel tube and the concrete. The finite element model (FEM) and meshes are shown in Figure 3.

\subsubsection{The finite element simulation process}

Currently there are two major approaches for calculating fire resistance of CFST columns.

(1) A fixed load is applied to a component first. This is followed by elevating the temperature as a function of time until failure occurs, by which the fire resistance time of the member under the fixed load is obtained ${ }^{[10,22]}$.

(2) For a given temperature field calculated at a given time-lapse of fire, the load-deformation curve is calculated by applying displacement loading, from which the ultimate loading capacity under the given temperature field or a required fire resistance time is obtained (e.g. ${ }^{[23]}$ ). Repeating this procedure by setting different times and temperature, the fire resistance time of a given load can be obtained via interpolation.

The first approach takes into account the full history of a fire and can follow the standard fire test curves 
well. The second approach ignores the deformation accumulated during the course of temperature rising. However, it is simple and has good convergent rate. In this paper, the first approach is adopted to trace the time dependent responses of CFST subject to both elevated temperature and preload.

\subsection{Validation of the Finite Element model}

To the authors' best knowledge, apart from the new test results reported in the companion paper ${ }^{[24]}$ of this work, there is no fire resistance test on preloaded CFST available in the literature for validating the model described above. To conduct a more comprehensive validation, comparisons are made first between the simulation results and those from some special cases that, i.e., preloaded CFST at room temperature and fire resistance of CFST without preload, of which experimental results are available in the literature. Comparisons are made then with the new experimental results in the companion paper ${ }^{[24]}$ that are for fire resistance of CFST with preload.

\subsubsection{CFST with preload at room temperature}

The preloaded short columns tested by Zha ${ }^{[25]}$ and slender columns tested by Huang ${ }^{[26]}$ at room temperature, are chosen to validate the proposed FE model. The design parameters of the columns are shown in Table 1, where, $D, t$ and $L$ denote diameter of column, thickness of steel tube and length of column, respectively; $\lambda$ is slenderness ratio; $\beta\left(=N_{\text {pre }} / \varphi_{s} N_{0, S}\right)$ is the preload ratio where $N_{\text {pre }}$ is the preload applied to steel tube; $\varphi_{s}$ is the stability factor of steel column without considering preload; and $N_{0, s}$ is the characteristic plastic resistance of steel tube; $f_{\mathrm{y}}$ is the yield strength of steel and $f_{\text {cu }}$ is the cube strength of concrete.

Table 1 Parameters of the columns

\begin{tabular}{cllcccccccc}
\hline $\begin{array}{c}\text { Specimens } \\
\text { ID }\end{array}$ & Ref. & NO & $\begin{array}{c}D \\
/ \mathrm{mm}\end{array}$ & $\begin{array}{c}t \\
/ \mathrm{mm}\end{array}$ & $\begin{array}{c}L \\
/ \mathrm{mm}\end{array}$ & $\lambda$ & $\beta$ & $\begin{array}{c}N_{\text {pre }} \\
/ \mathrm{kN}\end{array}$ & $\begin{array}{c}f_{\mathrm{y}} \\
/ \mathrm{MPa}\end{array}$ & $\begin{array}{c}f_{\text {cu }} \\
/ \mathrm{MPa}\end{array}$ \\
\hline Short & {$[25]$} & ZNS1 & 133 & 4.5 & 466 & 14 & 0.0 & 0 & 325 & 42.2 \\
Short & {$[25]$} & ZNS3 & 133 & 4.5 & 466 & 14 & 0.2 & 116.8 & 325 & 42.2 \\
Slender & {$[26]$} & H-D1 & 108 & 4.0 & 1944 & 72 & 0.24 & 41.65 & 336 & 54.9 \\
Slender & {$[26]$} & H-D2 & 108 & 4.0 & 1944 & 72 & 0.48 & 83.3 & 336 & 54.9 \\
\hline
\end{tabular}

In the simulations, the columns are preloaded first as specified in Table 1. Displacement loading is then imposed and the total axial force is calculated. The dilation angle in the concrete damaged plasticity model takes 30 and 40, respectively, to compare with the experimental results. The load-deformation curves for short and slender CFST columns from the FEM are compared with the test results in Figure 4. It can be observed from the comparisons that the dilation angle has certain influence on the posterior part of the load-deformation curves, while has little influence on the ultimate bearing capacity. For this reason and simplicity, dilation angle $\Psi=40$ is used in all calculations in the following sections.

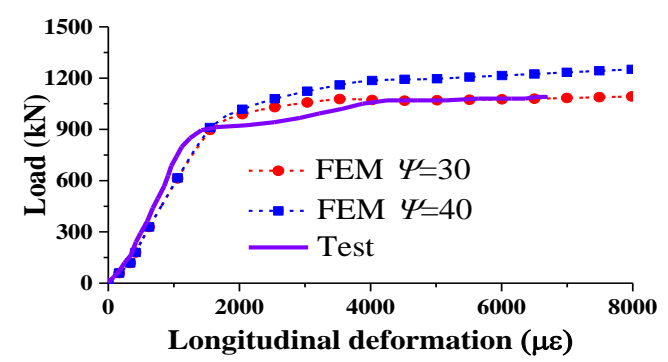

a) ZNS1

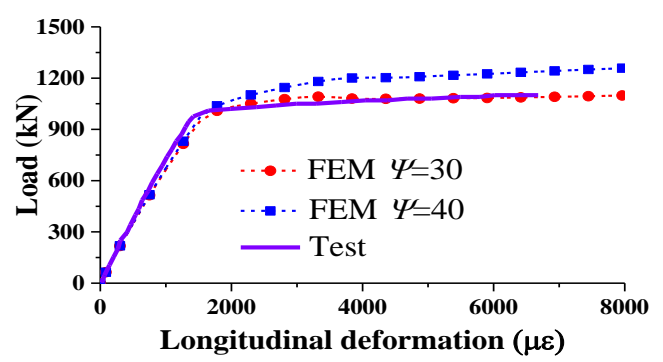

b) ZNS3 


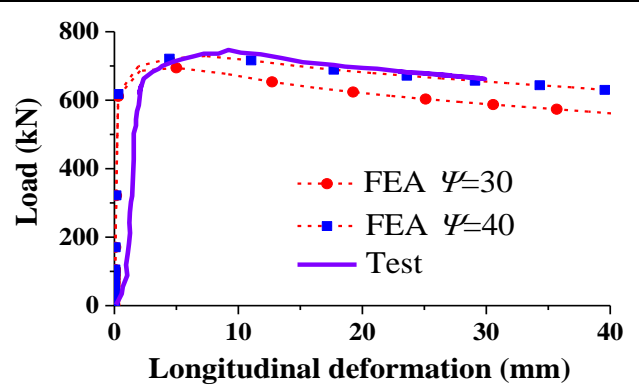

c) H-D1

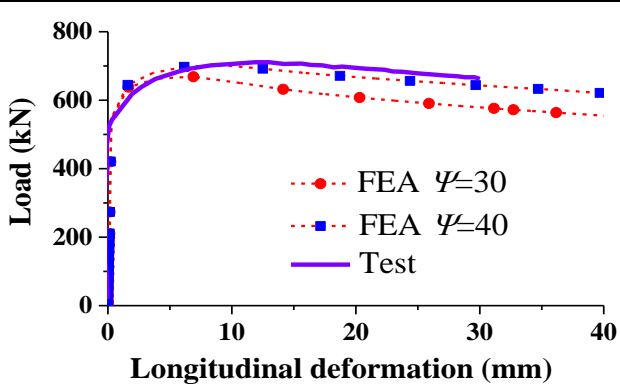

d) H-D2

Figure 4. Comparison of test and simulation results

\subsubsection{CFST under fire without preload}

To validate the finite element model for fire resistance analysis, the slender CFST columns tested by Lie ${ }^{[27]}$ and Romero ${ }^{[28]}$ are chosen first to compare with the simulation results. Details of the columns are presented in Table 2, where $f_{\mathrm{c}}$ is the cylinder strength of concrete and $T$ denotes fire resistance time.

Table 2 Design details of the columns tested by Lie and Romero

\begin{tabular}{cccccccccc}
\hline $\begin{array}{c}\text { Specimens } \\
\text { ID }\end{array}$ & Ref. & $\begin{array}{c}D \\
/ \mathrm{mm}\end{array}$ & $\begin{array}{c}t \\
/ \mathrm{mm}\end{array}$ & $\begin{array}{c}L \\
/ \mathrm{mm}\end{array}$ & $\begin{array}{c}f_{y} \\
/ \mathrm{MPa}\end{array}$ & $\begin{array}{c}f_{\mathrm{c}} \\
/ \mathrm{MPa}\end{array}$ & $\begin{array}{c}\text { Load } \\
/ k N\end{array}$ & $\begin{array}{c}T \\
/ \mathrm{Min}\end{array}$ \\
\hline C11- Lie & {$[26]$} & 219.1 & 4.78 & 3810 & 350 & 31.0 & 492 & 35 & 80 \\
\hline C159-6-3-30-0-40 & {$[27]$} & 159.0 & 6.00 & 3180 & 337.8 & 35.75 & 396 & 56 & 25 \\
\hline $\mathrm{C} 159-6-3-80-0-20$ & {$[27]$} & 159.0 & 6.00 & 3180 & 341.4 & 71.14 & 335 & 56 & 38 \\
\hline
\end{tabular}

The comparisons of the temperature field and the vertical deformation at the top end of columns C11-Lie are shown in Figure 5. The comparisons for columns C159-6-3-80-0-20 and C159-6-3-80-0-40 tested by Romero $^{[28]}$ are shown in Figure 6, which shows again good agreement between the two approaches. It is evident that the computed temperature field and the top vertical displacement agree well with the test results, which suggests that the simulations are sufficiently accurate.

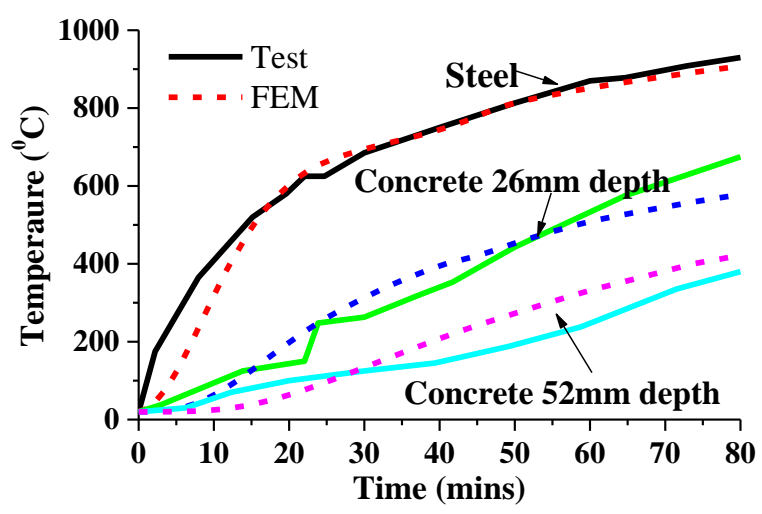

a) Temperature field

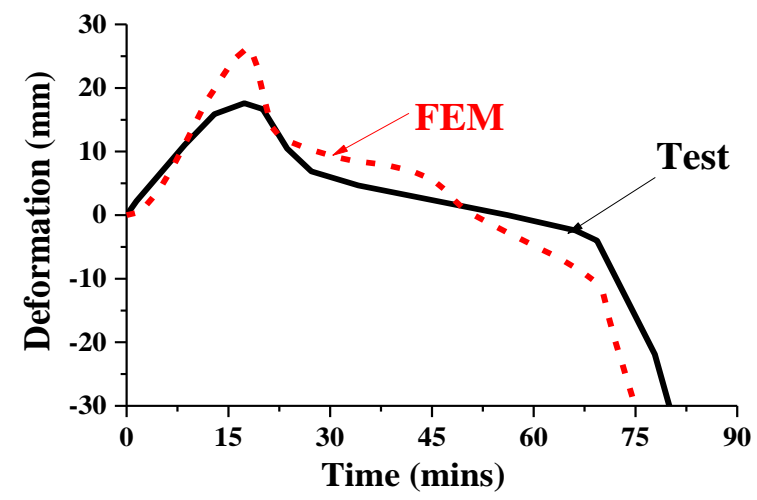

b) C11-Lie

Figure 5 Comparison of the test and simulation results 


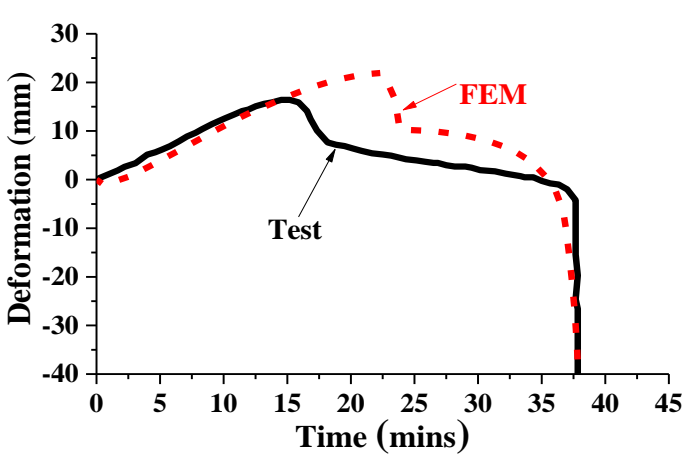

a) $\mathrm{C} 159-6-3-80-0-20$

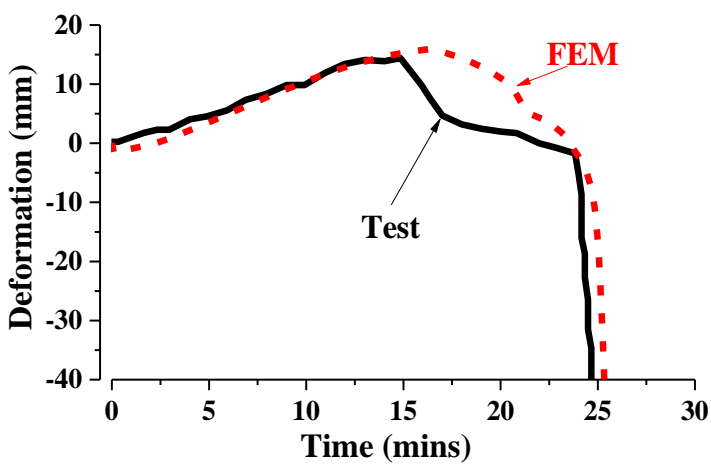

b) C159-6-3-80-0-40

Figure 6. Comparison of the top end vertical displacement

In general, the current finite element solutions compare well with the test results. The deformation curves show that the top ends of the columns experience an extension (moving upwards) initially as the temperature increases and displaces then in the opposite direction (moving downwards) after a peak value is reached. The early extension of the columns is due to thermal expansion that is later subsided by the increased axial contraction due to the axial force and softening of the materials caused by the elevated temperature. The columns continue to be shortened until an abrupt drop (sudden increase of contraction) of the deformation occurs.

\subsubsection{CFST under fire with preload}

From the comparisons made for the two special cases in Sections 2.2.1 and 2.2.2, it is clear that the proposed FE model can be used to simulate the mechanical behavior of preloaded CFST columns at room temperature and fire resistance of CFST columns without preload. To further validate the model, new experimental tests were carried out on slender CFST columns subject to both fire and preload and reported in the companion paper ${ }^{[24]}$. The details of the 12 slender columns tested by the authors can be found in Table 1 of ${ }^{[24]}$, where the experimental procedure, the application of preload and loads, measurement of temperature and fire resistance can also be found. For the sake of convenience, the specifications of the 12 columns are presented again in this paper in Table 3. In the Table $N_{\text {pre }}$ is the preload applied to steel tube; $N$ is the total axial load applied to column; $T$ is the fire resistance time.

Table 3 Details of the experimentally tested columns

\begin{tabular}{ccccccc}
\hline $\begin{array}{c}\text { Specimen } \\
\text { ID }\end{array}$ & $\begin{array}{c}\text { Steel tube } \\
\text { dimensions } \\
D \times d_{\mathrm{s}} \times H(\mathrm{~mm})\end{array}$ & $\begin{array}{c}\text { Preload } \\
\text { Ratio, } \beta\end{array}$ & $\begin{array}{c}\text { Preload } \\
N_{\text {pre }} / \mathrm{KN}\end{array}$ & Load ratio, $r$ & $\begin{array}{c}\text { Total load } \\
N_{t} / \mathrm{KN}\end{array}$ & $\begin{array}{c}T \\
/ \text { Min }\end{array}$ \\
\hline $\mathrm{C} 11$ & $219 \times 4.0 \times 3470$ & 0 & 0 & 0.3 & 395.5 & 47.0 \\
$\mathrm{C} 12$ & $219 \times 4.0 \times 3470$ & 0.2 & 145.4 & $\underline{0.45}\left(0.3^{*}\right)$ & $\underline{595.0}\left(395.5^{*}\right)$ & 29.0 \\
$\mathrm{C} 13$ & $219 \times 4.0 \times 3470$ & 0.4 & 290.8 & $\underline{0.40}\left(0.3^{*}\right)$ & $\underline{531.0}\left(395.5^{*}\right)$ & 22.5 \\
$\mathrm{C} 14$ & $219 \times 4.0 \times 3470$ & 0.5 & 363.6 & 0.3 & 395.5 & 43.0 \\
$\mathrm{C} 21$ & $219 \times 4.0 \times 3470$ & 0 & 0 & 0.5 & 659.2 & 22.2 \\
$\mathrm{C} 22$ & $219 \times 4.0 \times 3470$ & 0.2 & 145.4 & 0.5 & 659.2 & 21.8 \\
$\mathrm{C} 23$ & $219 \times 4.0 \times 3470$ & 0.4 & 290.8 & 0.5 & 659.2 & 20.5 \\
$\mathrm{C} 24$ & $219 \times 4.0 \times 3470$ & 0.5 & 363.6 & 0.5 & 659.2 & 20.0 \\
$\mathrm{C} 31$ & $219 \times 4.0 \times 3470$ & 0 & 0 & 0.7 & 922.9 & 16.0 \\
$\mathrm{C} 32$ & $219 \times 4.0 \times 3470$ & 0.2 & 145.4 & 0.7 & 922.9 & 15.5
\end{tabular}




\begin{tabular}{lllllll} 
C33 & $219 \times 4.0 \times 3470$ & 0.4 & 290.8 & 0.7 & 922.9 & 10.0 \\
C34 & $219 \times 4.0 \times 3470$ & 0.5 & 363.6 & 0.7 & 922.9 & 13.4 \\
\hline
\end{tabular}

In Table 3, the load ratio and the total load of $\mathrm{C} 12$ and $\mathrm{C} 13$ have two values. The ones in the brackets with asterisks are the designed (expected) values, while during the tests, the achieved loads were, respectively, the underlined values due to some technical issues. Table 4 presents the comparisons of the vertical displacements at the top ends of the 12 columns. In general, the finite element results compare with the test ones reasonably well. In the experiments, the designed preload and total axial load on columns C12 and C13 were not achieved due to unexpected load surge. The two columns are simulated here with the achieved loads and preloads. It is found that the finite element results using the achieved loads also compare well with the test results.

Table 4 Comparison of the vertical deformation vs time

\begin{tabular}{llllll}
\hline \multirow{2}{*}{$\begin{array}{c}\text { Lad } \\
\text { ratio }\end{array}$} & 0.0 & 0.2 & Preload ratio & 0.4 & 0.5 \\
\hline
\end{tabular}
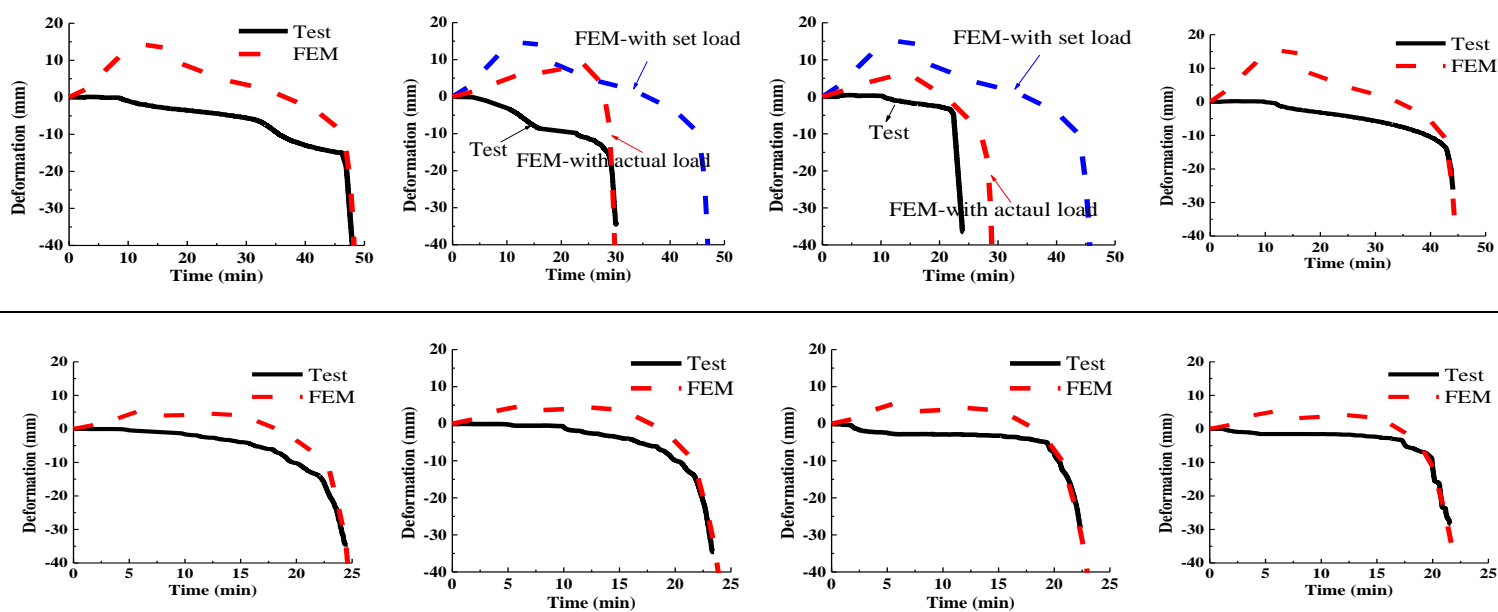

0.7
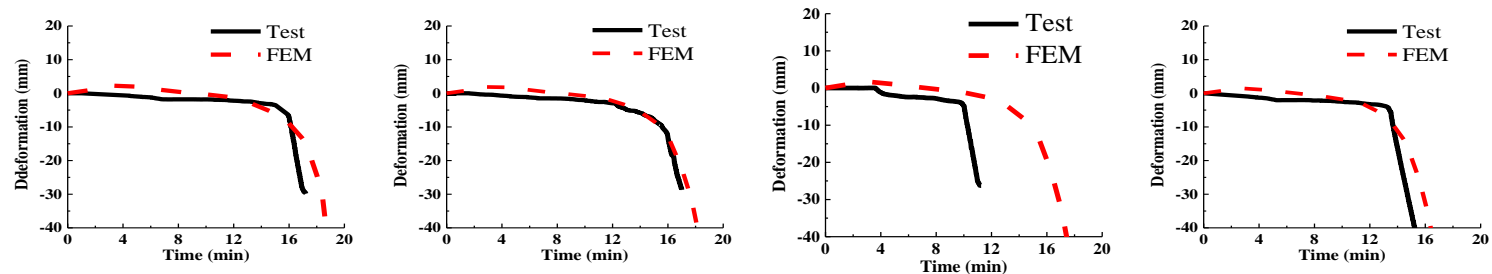

The average of the measured temperature of all the tested columns are compared with the predicted temperature in Figure 7a. The measured temperature of the steel tube is higher than the prediction from the FE model, which is partly attributed to that the thermocouples are directly exposed to the fire during the test. In general, the computed temperature field of the steel tube and the concrete agree with the measured temperature reasonably well. The comparisons of the fire-resistance time between the tests and the simulation results are shown in Figure 7b. For columns $\mathrm{C} 12$ and $\mathrm{C} 13$, the fire-resistance time predicted by the FEM model for the design load ratio $(r=0.3)$ and the achieved load ratio in the tests $(r=0.45$ for $\mathrm{C} 12$ and $r=0.40$ for $\mathrm{C} 13)$ are both shown in Figure 7b. It is evident that the predicted fire resistance times of all the design agree well with the test results. Hence, it can be concluded that the proposed FE model can be used to simulate fire resistance analysis of preloaded CFST. As expected, fire-resistance time decreases with the preload ratio, which will be further studied in the following sections. 


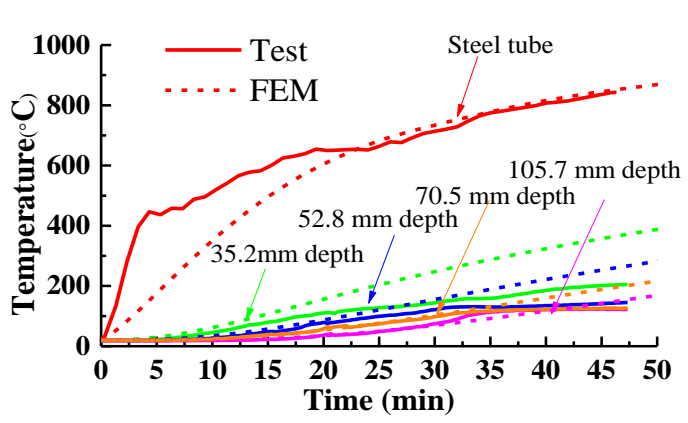

a) Temperature field

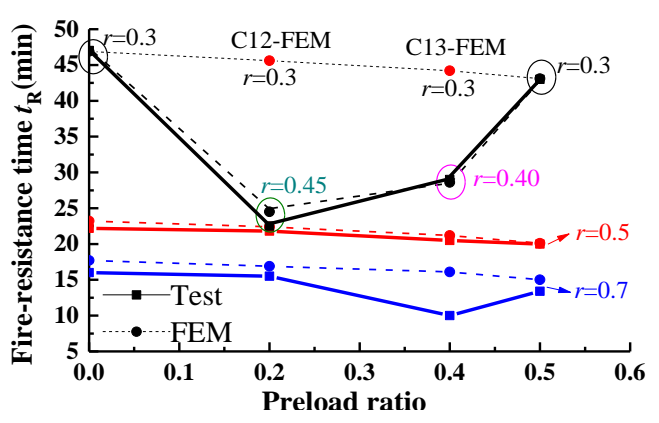

b) Fire-resistance time

Figure 7. Comparison of test and simulation results

\section{Effect of preload on fire resistance of CFST columns}

\subsection{Effect of preload on fire resistance of short columns}

After the validations in the previous section, the FE model is now applied to investigate the effect of preload on fire resistance of CFST columns. For short circular columns, the effect of column diameter D, load ratio $r=$ $N / N_{0}$, and preload ratio $\beta=N_{\text {pre }} / N_{0, S}$, are studied here. The chosen materials and column diameters are from those that are commonly used in practical design and are shown in Table 5, from which combinations of design parameters are determined by the uniform design method. Four columns are selected to be calculated using the finite element model, i.e. columns NO.343, NO.214, NO.131 and NO.422 where the three digits denote the respective concrete strength, steel grade and outer diameter of the steel tube chosen from materials 1 to 4 listed in Table 5. For example, the concrete strength, steel strength and diameter of NO.343 are $32.4 \mathrm{MPa}, 420 \mathrm{MPa}$ and $600 \mathrm{~mm}$, respectively.

Table 5 Design selections of CFST short columns

\begin{tabular}{ccccc}
\hline Design parameters & \multicolumn{4}{c}{ Selections of materials strength } \\
\cline { 2 - 5 } & 1 & 2 & 3 & 4 \\
\hline Compressive strength of Concrete/MPa & 20.1 & 26.8 & 32.4 & 38.5 \\
Yield stress of steel tube/MPa & 235 & 345 & 390 & 420 \\
Equivalent outer diameter of tube D/mm & 200 & 400 & 600 & 800 \\
\hline
\end{tabular}

The slenderness ratios of all the short columns are 15 and the thicknesses of all the steel tubes are $8 \mathrm{~mm}$. Load ratios $(r)$ of $0.5,0.6,0.7$ and 0.8 are considered, respectively, with a preload ratio of $0,0.2,0.4$ and 0.6 . It is assumed that the columns are heated following the ISO-834 standard fire curve. Figure 8 shows the fire resistance time-deformation curves of the four short columns subject to different load and preload ratios. It can be clearly seen from Figure 8 that for the short CFST columns, preload has no significant effect on their fire resistance time, which is consistent with the observation that preload has little influence on short columns at room temperature ${ }^{[11]}$. 


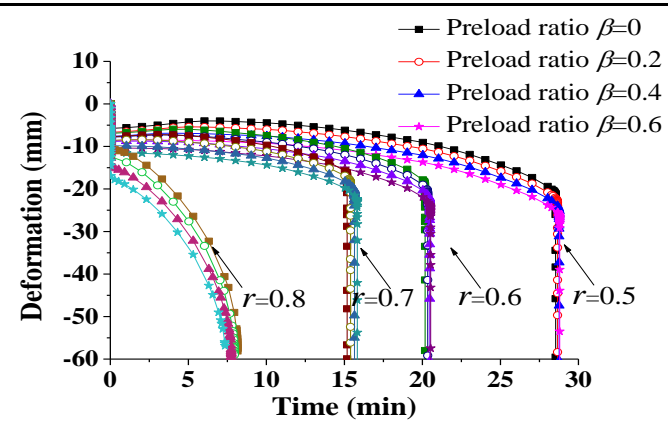

a) $\mathrm{NO} .343$

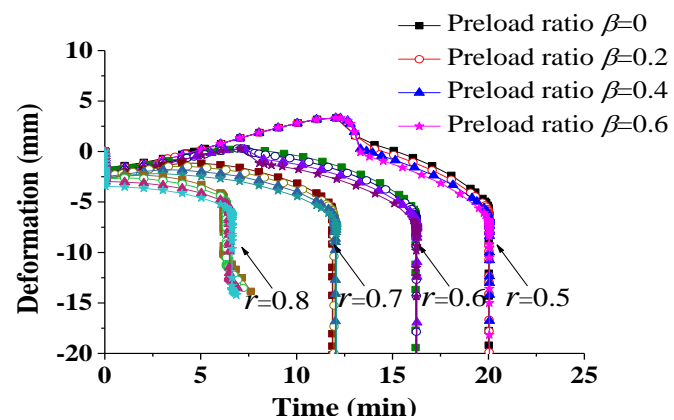

c) NO.131

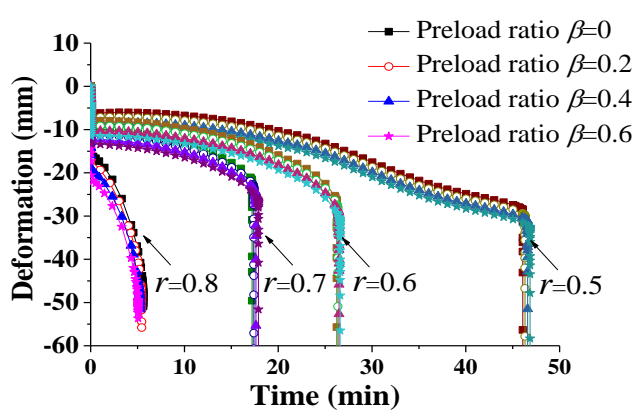

b) NO.214

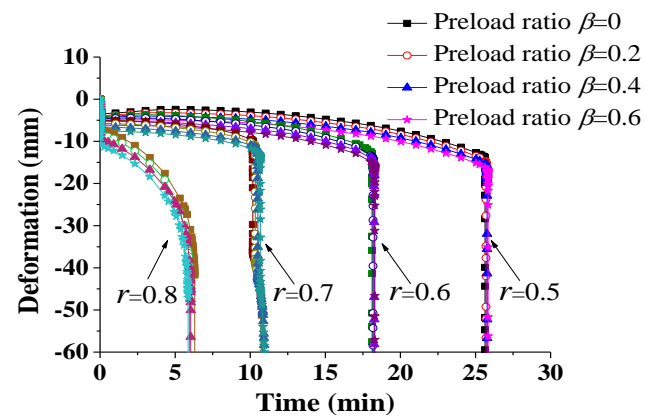

d) NO.422

Figure 8. The influence of preload on fire resistance of short CFST columns

\subsection{Effect of preload on fire resistance of slender columns}

Column NO.131 with various slender ratios are studied further in this section. The thickness of the steel tube is also $8 \mathrm{~mm}$, while the slender ratios of the columns are now 30,60, 90 and 120, respectively. The load ratios are 0.5, 0.6, 0.7 and 0.8, and the preload ratios are 0, 0.2, 0.4 and 0.6. Fire resistance of the columns considering above varying slenderness, load and preload ratios are calculated using the finite element model and shown in Table 6.

Table 6 Influence of preload on fire resistance of slender columns

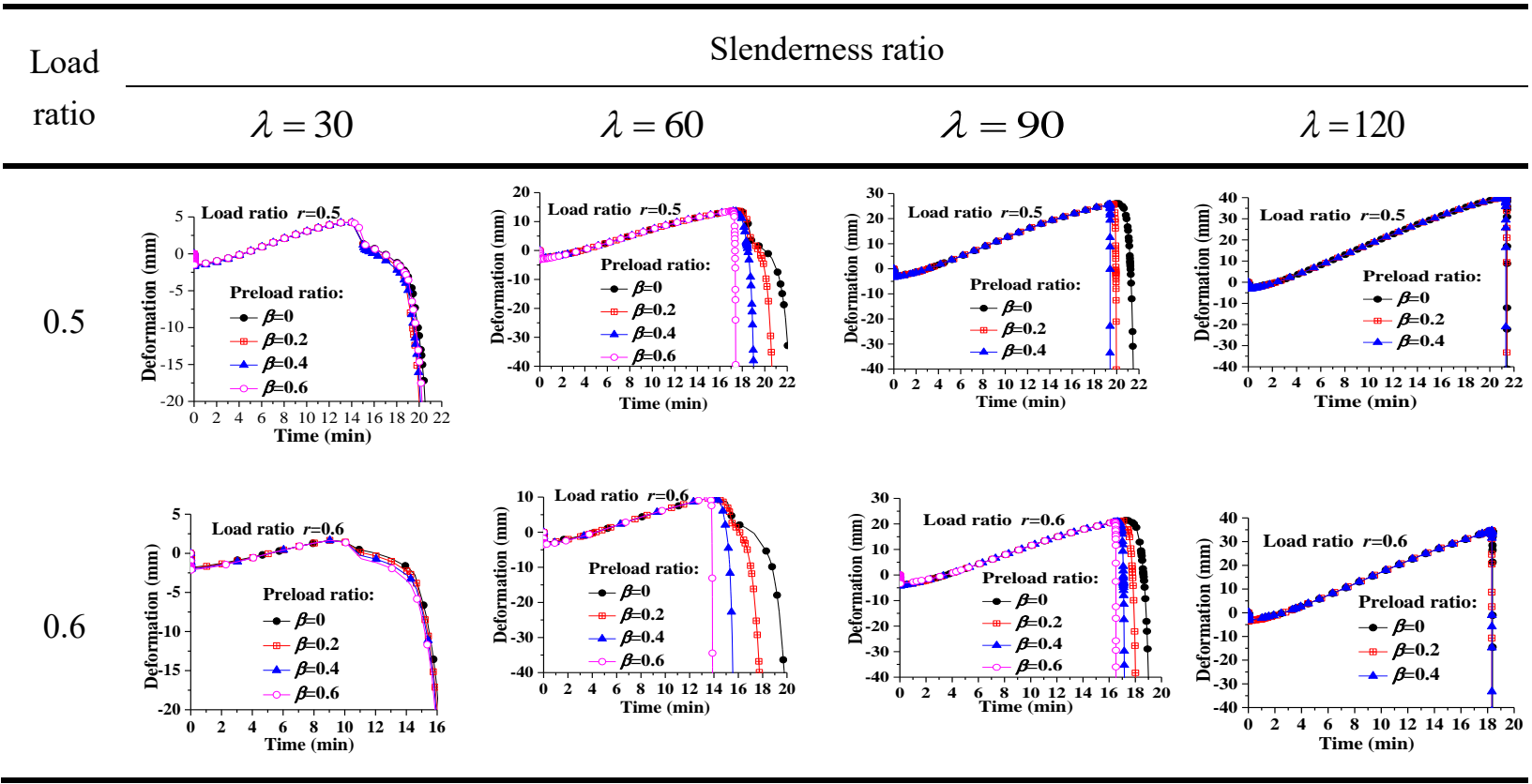


0.7
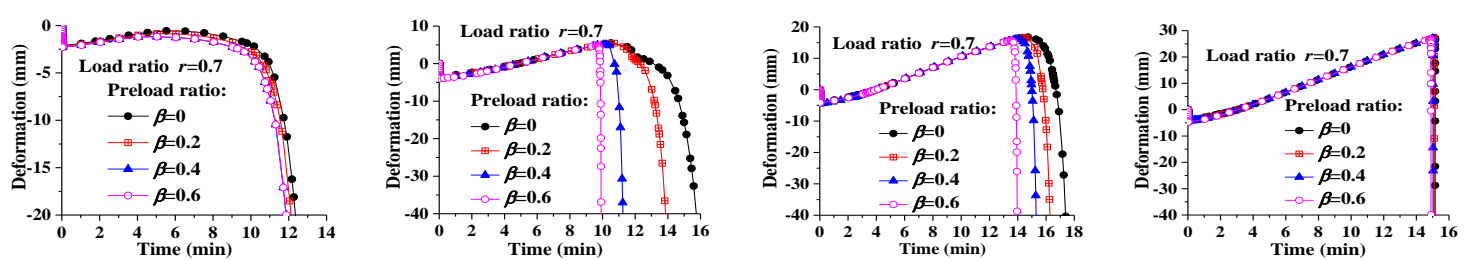

0.8
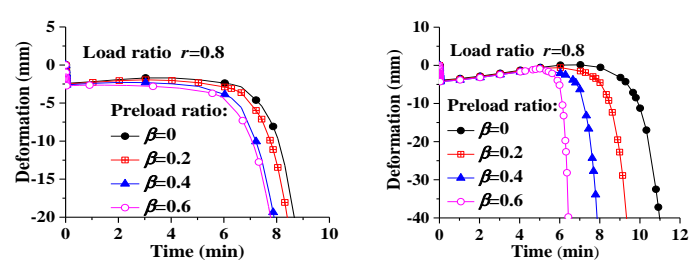

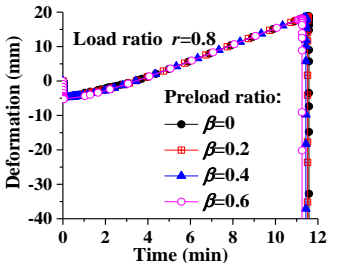

From Table 6, it can be seen that both the slenderness ratio and load ratio are influential factors for the fire resistance of the preloaded CFST columns. It can be concluded that the higher the preload ratio is, the shorter the fire resistance time will be when slenderness ratio is 60 or 90 . For example, the fire resistance time for $\beta=0$ is nearly twice as long as the time for $\beta=0.6$ when the load ratio is 0.7 or 0.8 and slenderness ratio is 60. However, when the slenderness ratio increases further after 90 , the effect of preload on fire resistance is significantly reduced, which suggests that stability of columns with a greater slenderness ratio is less sensitive to preload. The effect of preload on fire resistance also depends on the load ratios, i.e., a higher load ratio ( $r=0.7$, 0.8 ) results in greater preload effect on the fire resistance time. Further explanations of the above observations are given in Sections 3.3 and 4.

\subsection{Effects of preload on the behavior of CFST columns under fire}

To help with further understanding of the impact of preload on fire resistance of CFST columns, column C159-6-3-80-0-20 in Table 2 is studied again here. A preload of $135 \mathrm{kN}$ is applied to the steel tube and the total load is $335 \mathrm{kN}$ as applied in the test. The effect of preload on fire resistance of the CFST can be illustrated, as shown in Figure 9, by studying the vertical displacement of top end of the column with and without being preloaded. The vertical displacement curves have four distinctive stages (Fig.9a). Stage 1: when the column is subjected to fire in its early stage, the internal force on the preloaded steel tube and the axial deformation of the column are greater than those of the column without preload (Fig.9b and c). In this stage, due to the greater thermal expansion in the steel, slip occurs between the tube and the concrete causing detachment of the concrete from the rigid plate at the top. Stage 2: the top end of the steel tube moves downward very quickly due to the compressive load and the reduced stiffness of steel. The top rigid plate re-contacts the concrete core and the axial load is redistributed. Stage 3: the downward deformation of the top end continues with a much slower rate, as the steel tube and the concrete are now working together; Stage 4: failure occurs when the strength of the column is reached, as shown by the abrupt drop of the curves where the impact of preload is obvious. 


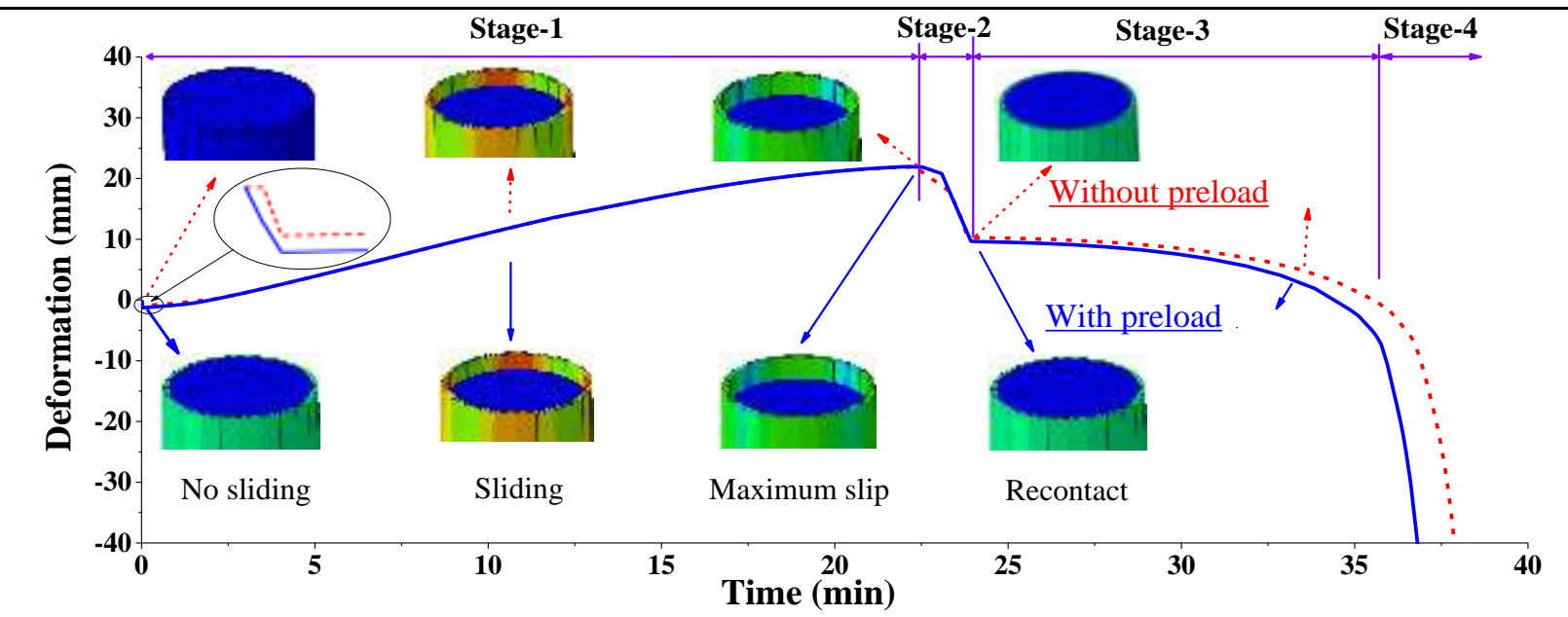

a) Top end vertical deformations of concrete and steel

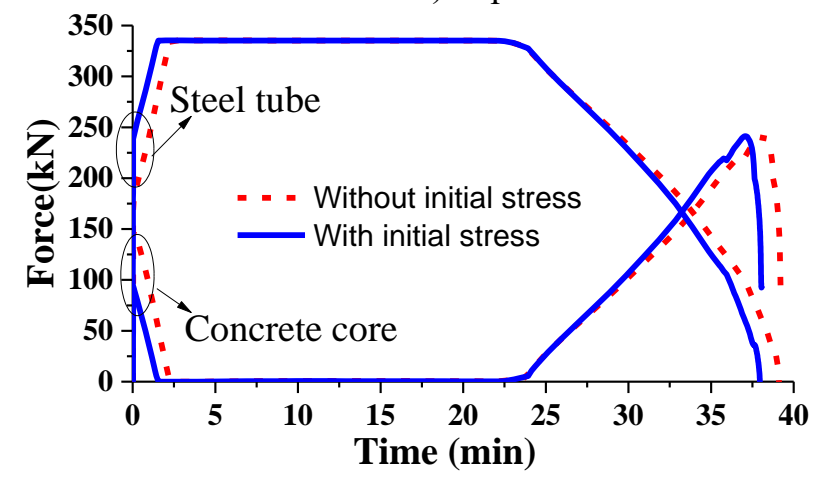

b) Comparison of internal force distribution

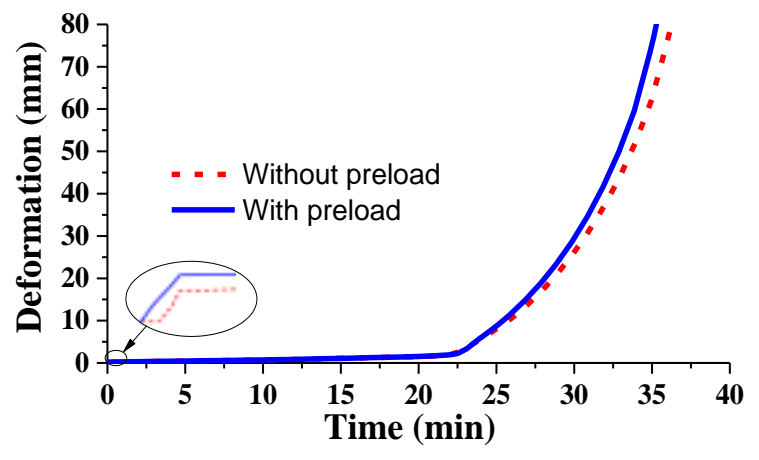

c) Comparison of lateral deformation

Figure 9. Comparisons of CFST columns with and without the effect of preload under fire

Figure $9 \mathrm{c}$ shows the lateral deformation at the mid-span of the column viz fire exposure time. It can be seen that the lateral deformation of the preloaded column is larger than that of the columns without preload. The comparisons clearly show that once the steel and concrete are working together, the preload has an impact on the internal force carried by the concrete core and also the lateral deformation of the column, which will affect its fire resistance time. According to Liew's formula ${ }^{[12]}$, at room temperature the preload in steel tubes affects mainly the calculation of the equivalent initial imperfections of CFST columns, thus the strength of short columns is not affected significantly by such imperfections. However, preload has a more pronounced effect on the axial capacity of intermediate and slender columns at room temperature. The same principle applies to preloaded CFST columns under fire.

\section{Calculation formulas for fire resistance of preloaded CFST}

\subsection{Bearing capacity of preloaded CFST at room temperature}

The above analyses have shown that preload has almost no effect on the strength of short CFST columns at elevated temperature. Therefore, the calculation formulas for the strength of short CFST without preload can be used directly for the CFST with preload. However, for preloaded slender CFST columns, both the experimental results in the companion paper ${ }^{[24]}$, and the simulations reported in this paper have shown that preload has to be considered. For CFST columns at room temperature, Liew ${ }^{[12]}$ et al proposed formulas for calculating stability factor of preloaded columns by considering preload as an equivalent form of initial bending denoted by a preload influence factor $\xi_{\text {pre }}$. The formulas are expressed based on Eurocode $4^{[29]}$, as follows. 


$$
\begin{gathered}
\varphi_{s c, p r e}=\frac{1}{\Phi_{p r e}+\sqrt{\Phi_{p r e}{ }^{2}-\bar{\lambda}_{s c}^{2}}} \leq 1.0 \\
\Phi_{p r e}=0.5\left[\bar{\lambda}_{s c}^{2}+\alpha\left(\xi_{p r e} \bar{\lambda}_{s c}-0.2\right)+1\right]
\end{gathered}
$$

where $\bar{\lambda}_{s c}=\sqrt{N_{0} / N_{c r}}$ is the slenderness ratio of a CFST column; $\alpha$ is the imperfection factor related to the type of steel, which takes 0.49 as recommended in Eurocode 4.

The effect of preload on bearing capacity is estimated as the effect of an equivalent initial eccentricity denoted by a preload influence factor $\xi_{\text {pre }}{ }^{[12]}$ as follows:

$$
\xi_{p r e}=\frac{1-N_{p r e} / N_{E k}}{1-N_{p r e} / N_{s, E k}} \geq 1.0
$$

Or

$$
\xi_{p r e}=\frac{1-N_{p r e} / N_{E k}}{1-N_{p r e} / N_{s, E k}}=\frac{1-\frac{N_{p r e}}{\varphi_{s} N_{0, s}} \cdot \frac{\varphi_{s} A_{s} f_{y}}{N_{E k}}}{1-\frac{N_{p r e}}{\varphi_{s} N_{0, s}} \cdot \frac{\varphi_{s} N_{0, s}}{N_{s, E k}}}=\frac{1-\beta \cdot \frac{\theta}{1+\theta} \cdot \frac{\varphi_{s}}{\varphi_{s c}}}{1-\beta}
$$

where, $\theta=f_{y} A_{s} / f_{c k} A_{c}$ is confining coefficient; $\beta=N_{p r e} / \varphi_{s} N_{0, s}$ is previously defined as preload ratio. $\varphi_{s}$ and $\varphi_{s c}$ are the stability factors of a steel column and CFST without considering preload, respectively. It is found from numerical calculations that the ratio, $\boldsymbol{\varphi}_{s} / \boldsymbol{\varphi}_{s c}$, of the steel tube and the CFST ranges from 0.9 to 1.1 . To simplify the calculations, the ratio is taken approximately as $1 \mathrm{in} \mathrm{Eq.} \mathrm{(4).} \mathrm{Thus,} \mathrm{the} \mathrm{preload} \mathrm{influence} \mathrm{factor} \mathrm{is}$ simplified, as shown in Eq.(5).

$$
\xi_{\text {pre }}=\frac{1-\beta \cdot \frac{\theta}{1+\theta} \cdot \frac{\varphi_{s}}{\varphi_{s c}}}{1-\beta} \approx \frac{1-\beta \cdot \alpha_{s}}{1-\beta} \quad\left(\alpha_{s}=\frac{\theta}{1+\theta}\right)
$$

To verify the accuracy of the simplified factor, the preload reduction factor, $\eta_{p r e}=\varphi_{s c, p r e} / \varphi_{s c}$, where $\varphi_{s c}$ is equal to $\varphi_{s c, p r e}$ when $\xi_{\text {pre }}$ is 1 , calculated by using the simplified preload influence factor (Eq.5) are compared with that calculated by using the original preload influence factor (Eq.4) for a range of slenderness $\operatorname{ratios}^{[11]}$, as shown in Error! Reference source not found.. It is evident that they agree with each other well. To confirm this further, 12 columns are chosen to validate the accuracy and applicability of the simplified factor. The columns are selected by the uniform design method, considering different diameters (ranged from $200 \mathrm{~mm}$ to $1200 \mathrm{~mm}$ at every $200 \mathrm{~mm}$ ), steel thickness (ranged from 3 to $18 \mathrm{~mm}$ in every $3 \mathrm{~mm}$ ), steel strength (yielding at $235 \mathrm{MPa}, 295 \mathrm{MPa}, 345 \mathrm{MPa}, 390 \mathrm{MPa}, 420 \mathrm{MPa}, 460 \mathrm{MPa}$ ) and concrete strengths (at 20.1 MPa, 26.8MPa, 32.4MPa, 38.5MPa, 44.5MPa, 50.2MPa). The comparisons are shown in Error! Reference source not found., where the mean value and the variance of the ratios of the preload reduction factor calculated using the original and the simplified forms are 0.9977 and $5.55 \times 10^{-5}$, respectively. The maximum error is less than $3 \%$. 


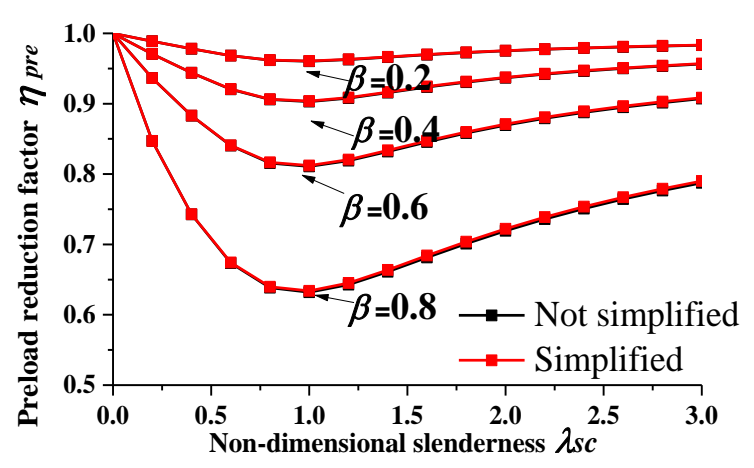

Figure 10 Comparison of preload reduction factor

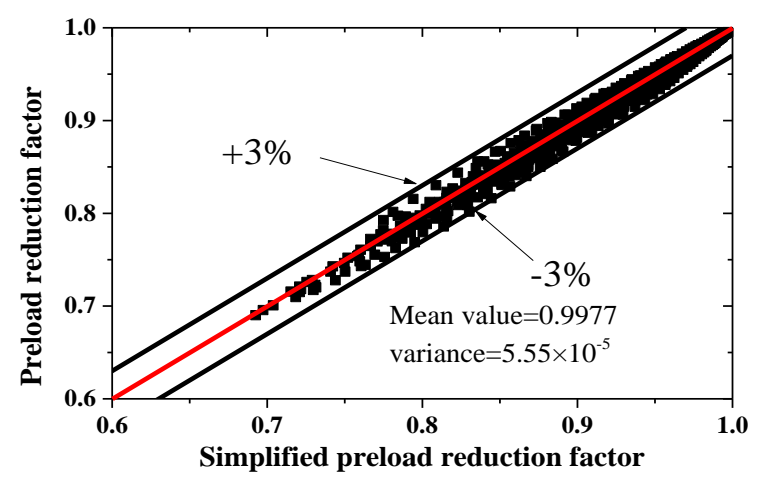

Figure 11 Error analysis of preload reduction factor

\subsection{Bearing capacity of preloaded CFST under fire}

In the authors' previous work ${ }^{[30]}$, a unified calculation method of CFST under fire was proposed, where average temperature rather than detailed temperature field was used in the temperature-dependent calculations. One of the obvious advantages of the method is that it does not require calculation of the complex non-uniform temperature distribution. The method provides equations for calculating average temperatures of steel and concrete. Equivalent strength and stiffness of steel and concrete are then calculated, respectively, at the average temperatures. The strength and stability of a CFST is finally calculated from the formulas, which were developed for CFST at room temperature, using the equivalent strength and stability factor estimated at the elevated average temperature. Detailed formulation and calculation steps can be found in $\mathrm{Yu}$ et $\mathrm{al}^{[30]}$, and the stability factor of CFST under fire without preload is as follows.

$$
\begin{gathered}
\varphi_{s c, T}=\frac{1}{\Phi_{0, T}+\sqrt{\Phi_{0, T}{ }^{2}-\bar{\lambda}^{2} s c, T}} \\
\Phi_{T}=0.5\left[\bar{\lambda}_{s c, T}^{2}+\alpha\left(\bar{\lambda}_{s c, T}-0.2\right)+1\right]
\end{gathered}
$$

where $\bar{\lambda}_{s c, T}$ is the normalized slenderness ratio under fire and is given by $\bar{\lambda}_{s c, T}=\sqrt{N_{0, T} / N_{c r, T}}$.

In this Section, the same procedure is followed to extend the application of Eqs. (1) and (2), which are the stability factors for preloaded columns at room temperature, to include columns at elevated temperature. To this end, the normalized slenderness ratio in the formula of stability factor at room temperature $\left(\bar{\lambda}_{s c}\right)$ is replaced by the normalized slenderness ratio at elevated temperature ( $\left.\bar{\lambda}_{s c, T}\right)$. From Eqs. (1) and (2), the stability factor formulas considering the effect of preload and fire can be expressed as follows:

$$
\begin{gathered}
\varphi_{s c, p r e, T}=\frac{1}{\Phi_{p r e, T}+\sqrt{\Phi_{p r e, T}^{2}-\bar{\lambda}_{s c, T}^{2}}} \\
\Phi_{p r e, T}=0.5\left[\bar{\lambda}_{s c, T}^{2}+\alpha\left(\xi_{p r e} \bar{\lambda}_{s c, T}-0.2\right)+1\right]
\end{gathered}
$$

where a preload influence factor $\xi_{\text {pre }}$, is introduced to account for the effect of preload. The distribution diagram of the stability factor $\varphi_{s c, p r e, T}$, as a function of slenderness ratio and fire exposure time, is shown in Error! Reference source not found.2. It can be seen that when the normalized slenderness ratio is either small or large, the stability factor is less sensitive to the preload ratio $\beta$, especially when the columns are under fire. This confirms the observations from the results presented in Table 6 where the effect of preload on the fire resistance of CFST columns is ignorable when the columns are short or have a slenderness ratio of 90 or above. 


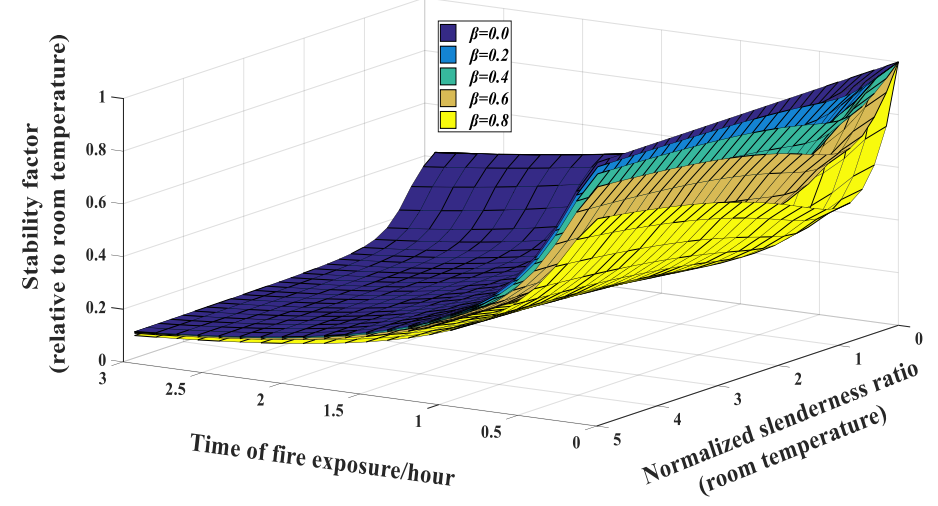

Figure 12. Distribution diagram of the stability coefficient

\subsection{Summary and validation of the unified formation for preloaded CFST columns}

Considering that the confinement effect of the steel tube decreases rapidly under fire and the authors' previous work ${ }^{[29]}$, the ultimate capacity of a CFST column is calculated by:

$$
\begin{gathered}
N_{u, T}=\varphi_{s c, p r e, T} N_{0, T} \\
N_{0, T}=A_{c} \bar{f}_{c k, \bar{T}_{c}}+A_{s} f_{y, \bar{T}_{s}}
\end{gathered}
$$

Where $\varphi_{s c, p r e, T}$ is the stability factor that considers the effect of preload and fire (see Eq.(8)); $N_{0, T}$ is the strength capacity of a CFST under fire; $A_{s}$ and $A_{c}$ are areas of steel and concrete, respectively. $\bar{f}_{c k, \bar{T}_{c}}$ is the equivalent strength of concrete at average temperature $\bar{T}_{c} ; f_{y, \bar{s}_{s}}$ is the equivalent strength of steel tube at average temperature $\bar{T}_{s}$. Further details can be found from the authors' previous work ${ }^{[30]}$.

To verify the accuracy of the calculation formulas, the ultimate bearing capacities calculated from Eq. (10) are compared with the results obtained from the previously validated FEM model for 130 CFST columns ( $f_{c k}=32.4 \mathrm{MPa}$ and $f_{y}=345 \mathrm{MPa}$ ) with preload ratios $0.0,0.2,0.4$ and 0.6 . The diameters of the columns are from $200 \mathrm{~mm}$ to $500 \mathrm{~mm}$ at every $100 \mathrm{~mm}$, and the respective slenderness ratio are $120,80,60$ and 68 . The fire resistance times ranging from zero to thirty minutes are considered at five-minute intervals. The comparisons are shown in Figure 13a. The mean value of the ratios of the numerical results to the results from the formulas and the variance are, respectively, 0.975 and 0.012 . The maximum error is within $7.5 \%$, illustrating that the predictions from the formulas are sufficiently accurate compared to the predictions from other researchers ${ }^{[30,31]}$. Furthermore, the ultimate bearing capacity calculated from Eqs.(10) and (12) are compared with the results obtained from the 12 columns in the companion paper ${ }^{[24]}$. The comparisons are shown in Figure $13 \mathrm{~b}$. The mean value of the ratios of the test results to the results from the formulas and the variance are, respectively, 1.094 and 0.039. The maximum error is less than $9.2 \%$. 


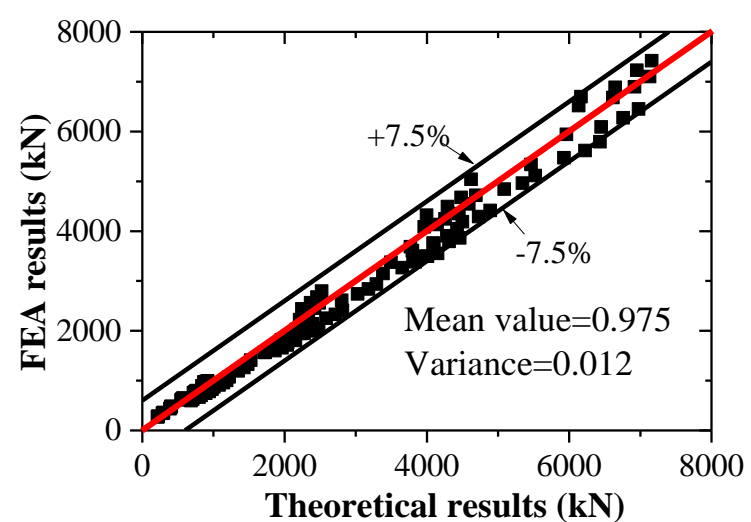

a) Theoretical and simulation results

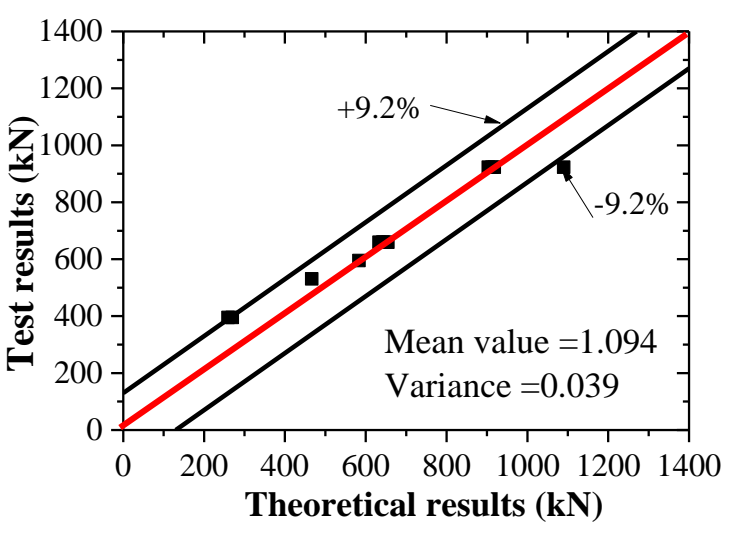

b) Theoretical and test results

Figure 13. Comparison of theoretical results with simulation results and test results

\section{Concluding Remarks}

A finite element model for fire resistance of both short and slender CFST columns with preload has been developed. Calculation formulas were also developed to predict fire resistance of preloaded CFST columns.

The FE model was validated against available numerical and experimental results, including results of CFST with preload at room temperature and CFST without preload at elevated temperature. The model was finally validated against new experimental results of preloaded CFST at elevated temperature.

Further applications of the validated model showed that preload had little impact on the fire resistance of short CFST columns, while the impact can be significant for slender ones. For a slenderness ratio of 60-90, it was obvious that the higher the preload ratio was, the shorter the fire resistance time would be. The impact of preload on the fire resistance of the columns becomes less significant if the slenderness ratio is further increased.

Analytical formulas were proposed to predict fire resistance of preloaded CFST columns. This was done by extending the average temperature method ${ }^{[30]}$ to unify the formulations for preloaded CFST columns at room and elevated temperature.

Since this is the first detailed modeling and formulation of fire resistance analysis of preloaded CFST columns, further work is immediately required to include CFST columns subjected to combined bending and compression and also CFST columns with fire protection.

\section{Acknowledgement}

The authors are grateful for the financial support from the National Natural Science Foundation of China (Grant Nos. 51508425, 51878518 and 51738011).

\section{References}

[1] Feng W, Zha XX. Finite element analysis on the creep behavior of axially-compressed concrete filled steel tube concrete filled steel tube members. Progress in Steel Building Structures 2011; 13(01):49-56. [in Chinese]

[2] Zhong ST. Concrete-filled steel tubular structures (3rd ed.). Beijing: Tsinghua University Press 2003. [in Chinese]

[3] Lie TT, Chabot M. A method to predict the fire resistance of circular concrete filled hollow steel columns. Journal of Fire Protection Engineering 1990; 2(4):158-167. 
[4] He JL, Zhong ST. Calculation of the thickness of the refractory protective layer of concrete filled steel tube columns. Journal of Harbin University of Civil Engineering and Architecture. 1999 ;(05):29-33. [in Chinese]

[5] Yang, YF, Feng F. Fire resistance of steel beam to square CFST column composite joints using RC slabs: Experiments and numerical studies." Fire Safety Journal, 2019;104: 90-108.

[6] Dai XH, Lam D. Shape effect on the behavior of axially loaded concrete filled steel tubular stub columns at elevated temperature. Journal of Constructional Steel Research, 2012; 73(73):117-127.

[7] Chung K, Park S, Choi S. Fire resistance of concrete filled square steel tube columns subjected to eccentric axial load. International Journal of Steel Structures 2009; 9(1):69-76.

[8] Hong S, Varma A H. Behavior of CFT Beam-Columns under Elevated Temperatures from Fire Loading. Structures Congress 2005:1-12.

[9] Espinos A, Romero ML, Hospitaler A. Advanced model for predicting the fire response of concrete filled tubular columns. Steel Construction 2010; 66(8):1030-1046.

[10] Yu M, Zha XX, Ye JQ, et al. Fire responses and resistance of concrete-filled steel tubular frame structures. International Journal of Structural Stability and Dynamics, 2010; 2(10):253-271.

[11] Xiong DX. Non-linear analysis of the initial stress effect on the behavior of concrete-filled square steel tubular members. Canadian Journal of Civil Engineering, 2005; 3(21):689-695.

[12] Liew J Y R, Xiong D X. Effect of preload on the axial capacity of concrete-filled composite columns. Journal of Constructional Steel Research, 2009, 65(3):709-722.

[13] Han LH, Yao GH. Effect of initial stress on bearing capacity of concrete-filled steel tubular beam-columns. China Civil Engineering Journal, 2003; 36(4):9-18. [in Chinese]

[14] Han LH, Zhao XL, Yang YF, et al. Experimental study and calculation of fire resistance of concrete-filled hollow steel columns. Journal of Structural Engineering, 2003; 129(3):346-356.

[15] Kim DK, Choi SM, Kim JH, et al. Experimental study on fire resistance of concrete-filled steel tube column under constant axial loads. International Journal of Steel Structures, 2005; 5(4):305-313.

[16] Yang H, Liu FQ, Zhang SM, et al. Experimental investigation of concrete-filled square hollow section columns subjected to non-uniform exposure. Engineering Structures, 2013; 48(Complete): 292-312.

[17] Kodur VKR. Performance-based fire resistance design of concrete-filled steel columns. Journal of Constructional Steel Research 1999; 59(12):1127-1134.

[18] Lie TT, Stringer DC. Calculation of the fire resistance of steel hollow structure section columns filled with plain concrete. Canadian Journal of Civil Engineering 1994; 21(3):382-385.

[19] CEN. EN 1994-1-2, Eurocode 4: design of composite steel and concrete structures, part 1.2: general rulesstructural fire design. Brussels (Belgium):Comité Européen de Normalisation; 2005.

[20] GB50010-2010. Code for design of concrete structures. Beijing, China: China Building Industry Press; 2011. [in Chinese] .

[21] Standards Swiss. Eurocode 3: Design of Steel Structures - Part 1-2: General Rules - Structural Fire Design. 2003.

[22] Han LH. Concrete-filled steel tube structure -- Theory and Practice (Second Edition). Beijing: The Science Publishing Company, 2007. [in Chinese]

[23] Yin J, Zha XX, Li LY. Fire resistance of axially loaded concrete filled steel tube columns. Journal of Constructional Steel Research, 2006;62(7):723-729.

[24] Yu M, Wang T, Huang WJ, Yuan,HQ, Ye JQ. Fire resistance of concrete-filled steel tube columns with preloads. Part I: Experimental Investigation (sumitted)

[25] Zha XX, Zhong ST. Influence of initial stress of steel tube on performance of concrete filled steel tube columns subjected to compression, bending and torsion. Journal of Harbin University of Civil Engineering and Architecture, 1997(02):45-53. [in Chinese] 
[26] Huang FY. Study on ultimate bearing capacity of concrete filled steel tube arch with initial stress. Fuzhou University, 2008. [in Chinese]

[27] Lie T T, Chabot M. Experimental studies on the fire resistance of hollow steel columns filled with plain concrete. Construction National Research Council Canada 1972; 5(3):398-418.

[28] Romero M L, Moliner V, Espinos A, et al. Fire behavior of axially loaded slender high strength concretefilled tubular columns. Journal of Constructional Steel Research, 2011,67(12):1953-1965.

[29] Standardization E C F. Design of composite steel and concrete structure-part1-21: general rules-structural fire design. 1994.

[30] Yu M, Zha XX, Ye JQ, et al. A unified method for calculating fire resistance of solid and hollow concretefilled steel tube columns based on average temperature. Engineering Structures 2014; 71:12-22.

[31] Wang YC, Kodur VKR. An approach for calculating the failure loads of unprotected concrete filled steel columns exposed to fire. Structural Engineering and Mechanics, 1999,7(2):127.

[32] Tan KH, Tang CY. Interaction model for unprotected concrete filled steel columns under standard fire conditions. 2004,130(9):1405-1413. 